\title{
A RECONFIGURAÇÃO DA POLÍTICA DE ASSISTÊ̂NCIA ESTUDANTIL NA UNIVERSIDADE FEDERAL DO ACRE
}

\author{
Adão Rogério Xavier Silva \\ Mark Clark Assen de Carvalho \\ Rafael Marques Gonçalves
}

Resumo

O presente artigo tem por objetivo analisar a reconfiguração da Política de Assistência Estudantil (PAE) na Universidade Federal do Acre (UFAC), no contexto de execução do Programa Nacional de Assistência Estudantil (PNAES), tendo como marco de referência o ano de 2013. Como aporte teórico-metodológico, a pesquisa fundamentou-se na Abordagem do Ciclo de Política na perspectiva de Mainardes (2006) referenciado em Ball (1994), cujas fontes primárias de análise foram documentos institucionais. Nesse estudo, os resultados são apresentados por meio do delineamento do contexto da prática. A partir das análises empreendidas, conclui-se que dois foram os elementos externos que influenciaram a reconfiguração da política de assistência estudantil na UFAC, a saber: o financiamento das Instituições Federais de Ensino Superior (IFES) e as políticas de expansão da oferta do ensino superior nas universidades públicas federais. No que refere ao elemento interno, considerado como movimento inicial do contexto da prática, tem-se a criação de um órgão executivo especifico para gestão/execução das Políticas de Assistência Estudantil, a Pró-Reitoria de Assuntos Estudantis (PROAES), que passará a gerir o conjunto das ações voltadas à materialização da política de assistência estudantil na UFAC.

Palavras-chave: Política de Assistência Estudantil; PNAES; Acesso e Permanência; Educação Superior; Universidade Federal do Acre.

\section{THE RECONFIGURATION OF THE STUDENT ASSISTANCE POLICY AT THE FEDERAL UNIVERSITY OF ACRE}

\begin{abstract}
This article aims to analyze the reconfiguration of the Student Assistance Policy (PAE) at the Federal University of Acre (UFAC), in the context of the execution of the National Student Assistance Program (PNAES), having the year 2013 as a reference point. As a theoretical-methodological approach, the research was based on the Policy Cycle Approach from the perspective of Mainardes (2006) referenced in Ball (1994), whose primary sources of analysis were institutional documents. In this study, the results are presented by outlining the context of the practice. Based on the analyzes carried out, it is concluded that two external elements influenced the reconfiguration of the student assistance policy at UFAC, namely: the financing of the Federal Higher Education Institutions (IFES) and the policies for expanding the supply of education higher in federal public universities. With regard to the internal element, considered as an initial movement in the context of the practice, there is the creation of a specific executive body for the management / execution of Student Assistance Policies, the Dean of Student Affairs (PROAES), which will become manage the set of actions aimed at materializing the student assistance policy at UFAC.
\end{abstract}

Keywords: Student Assistance Policy; PNAES; Access and Permanence; College education; Federal University of Acre. 


\section{LA RECONFIGURACIÓN DE LA POLÍTICA DE ASISTENCIA ESTUDIANTIL EN LA UNIVERSIDAD FEDERAL DE ACRE}

Resumen

Este artículo tiene como objetivo analizar la reconfiguración de la Política de Asistencia al Estudiante (PAE) en la Universidad Federal de Acre (UFAC), en el contexto de la ejecución del Programa Nacional de Asistencia al Estudiante (PNAES), teniendo el año 2013 como punto de referencia. Como contribución teórico-metodológica, la investigación se basó en el Enfoque del Ciclo de Políticas desde la perspectiva de Mainardes (2006) al que se hace referencia en Ball (1994), cuyas principales fuentes de análisis fueron los documentos institucionales. En este estudio, los resultados se presentan delineando el contexto de la práctica. Con base en los análisis realizados, se concluye que dos elementos externos influyeron en la reconfiguración de la política de asistencia al estudiante en UFAC, a saber: el financiamiento de las Instituciones Federales de Educación Superior (IFES) y las políticas para expandir la oferta de educación más alto en universidades públicas federales. Con respecto al elemento interno, considerado como un movimiento inicial en el contexto de la práctica, existe la creación de un cuerpo ejecutivo específico para la gestión / ejecución de las Políticas de Asistencia Estudiantil, el Decano de Asuntos Estudiantiles (PROAES), que se convertirá gestionar el conjunto de acciones dirigidas a materializar la política de asistencia al estudiante en UFAC.

Palabras clave: Política de Asistencia al Estudiante; PNAES; Acceso y Permanencia; Educación Universitaria; Universidad Federal de Acre.

\section{INTRODUÇÃO}

O Programa Nacional de Assistência Estudantil (PNAES) instituído em 2008, é uma política pública da educação superior executada no âmbito do Ministério da Educação (MEC), estruturada com o objetivo de ampliar as condições de permanência dos estudantes regularmente matriculados em cursos de graduação presencial das Instituições Federais de Ensino Superior (IFES).

A formulação do texto desta política origina-se, preliminarmente, nas contribuições do Fórum Nacional de Pró-Reitores de Assuntos Comunitários e Estudantis (FONAPRACE), instituído no ano 1987. Assim, pode-se reconhecê-lo com um dos significativos frutos dos Encontros Nacionais de Pró-Reitores de Assuntos Comunitários e Estudantis e dos encontros realizados pela Associação Nacional dos Dirigentes das Instituições Federais de Ensino Superior (ANDIFES). Desse modo, o PNAES representa a conquista da luta coletiva de grupos organizados, especialmente do ANDIFES, FONAPRACE e UNE.

A proposta do PNAES tem por embasamento as pesquisas realizadas em âmbito nacional nos anos de 1997 e 2004, as quais contribuíram para traçar o perfil socioeconômico e cultural dos estudantes de graduação das IFES públicas. Tais pesquisas possibilitaram diagnosticar a situação dos estudantes e elaborar um texto fundamentado, de modo que a proposta apresentada ao MEC se constituiu no próprio Programa (FONAPRACE, 2008).

$\mathrm{Na}$ UFAC, locus onde a pesquisa se ambienta, a materialização física/financeira do PNAES, remonta os primeiros anos da execução do programa, isso é, no exercício dos anos de 2008, conforme se verifica através da Ação: 4002 - Assistência ao Estudante do Ensino de Graduação ${ }^{1}$ e 4002 - Assistência ao Estudante de Ensino Superior² ; e Unidade Orçamentária: 26275 -

\footnotetext{
${ }^{1}$ Identificação referente aos períodos de 2008 a 2011.

2 Identificação referente aos períodos de 2012 a 2019.
} 
Fundação Universidade Federal do Acre, disponível no portal do Sistema Integrado de Planejamento e Orçamento (SIOP), bem como no Relatório de Gestão da UFAC - 2008.

Nesse contexto, identificou-se um montante de R \$: 360.000,00 (trezentos e sessenta mil reais) a serem utilizados nos limites da então Portaria Normativa n ${ }^{\circ}$ 39/2007 de 12 de dezembro do MEC, e posteriormente elevada para Decreto Lei no 7234/2010 de 19 de julho. Estes dois documentos se configuram na chamada terceira fase (atual estágio de desenvolvimento) das Políticas de Assistência Estudantil no Brasil conforme aponta Kowalski (2012).

Seguindo na esteira das análises de Kowalski (2012), Xavier Silva (2019) discorre que,

Diferentemente das duas fases anteriores, que não dispunham de um dispositivo legal de âmbito nacional voltado exclusivamente para a assistência estudantil, a terceira e atual fase dispõe. Sua ocorrência dá-se em confluência com o período de expansão e reestruturação das IFES e segue até os dias atuais. Observa-se, nesta fase, a institucionalização do PNAES em sua forma Normativa e, posteriormente, em Decreto Lei, que instrumentaliza e consolida a garantia formal ao direito à assistência estudantil, possibilitando a inclusão de uma parcela da sociedade que não tinha expectativa de acesso à educação superior pública e de permanência nesta (XAVIER SILVA, 2019, p.41).

Nos limites dessa análise, busca-se, aqui, identificar e estabelecer uma relação entre as influências externas dessa reconfiguração, concatenando-as ao contexto da prática, em especial àquela que foi a primeira ação objetivada pela UFAC, ou seja, a criação de um órgão executivo especifico para gestão, execução e coordenação da materialização das Políticas de Assistência Estudantil no âmbito da IES.

\section{A RECONFIGURAÇÃo DA POLÍTICA DE ASSISTÊNCIA ESTUDANTIL}

Verificou-se, na análise documental, que no penúltimo mês do exercício de 2012, ocorreu uma reestruturação relativa às questões do planejamento e execução da Política de Assistência Estudantil (PAE) na UFAC. Tratou-se da criação de um órgão executivo específico à sua gestão, a Pró-Reitoria de Assuntos Estudantis (PROAES) ${ }^{3}$, de forma que a PAE, na UFAC, configurou-se a partir dos anos 2013, período no qual, de fato, a PROAES inicia suas atividades enquanto próreitoria de natureza acadêmica.

Nota-se, nesta conjuntura, uma consonância com o contexto das reconfigurações ocorridas também no cenário da educação superior nacional, especialmente no campo do financiamento das Instituições Federais de Ensino Superior (IFES), bem como das políticas educacionais de ampliação do acesso ao ensino superior nacional, principais elementos que impulsionaram o que poderíamos até chamar de democratização da educação superior pública no Brasil.

No que tange ao elemento financiamento das IFES, a Tabela 1 exibe dados desta evolução orçamentária no período em questão. Consta que, entre os anos 2008 e 2013, teve-se uma elevação significativa de $60,84 \%$ dos recursos destinados às IFES, expressos pelos acréscimos oriundos de 0,19\% do Produto Interno Bruto (PIB) brasileiro, 0,99\% do Fundo de Público Federal (FPF) e $2,7 \%$ dos impostos arrecadados. Esse cenário é totalmente distinto do que se tinha no período de

\footnotetext{
${ }^{3}$ Criada a partir da Resolução no 99 de 29 de novembro de 2012 do Conselho Universitário (CONSU).
} 
1996 até o início dos anos 2000, em que o crescimento econômico não fora compensando/redistribuído ao financiamento da educação superior ${ }^{4}$.

Tabela 1: Recursos das IFES como percentual do PIB, das despesas correntes do FPF e da arrecadação de impostos da união (valores em $\mathbf{R} \$$ milhões)

\begin{tabular}{cccccccc}
\hline \multirow{2}{*}{ Ano } & \multirow{2}{*}{ PIB } & \multirow{2}{*}{ Desp. Corr. do FPF } & \multirow{2}{*}{ Impostos } & \multicolumn{5}{c}{ IFES } \\
\cline { 5 - 8 } & & & & Recursos & \% PIB & \% FPF & \% Impostos \\
\hline 2008 & 4.114 .507 & 737.871 & 365.419 & $\mathbf{2 4 . 5 1 8}$ & 0,60 & 3,32 & 6,7 \\
2009 & 4.191 .329 & 788.277 & 334.020 & $\mathbf{2 8 . 8 7 2}$ & 0,69 & 3,66 & 8,6 \\
2010 & 4.643 .910 & 818.267 & 345.066 & $\mathbf{3 2 . 9 2 1}$ & 0,71 & 4,02 & 9,5 \\
2011 & 4.785 .677 & 843.430 & 411.134 & $\mathbf{3 5 . 1 5 1}$ & 0,73 & 4,17 & 8,5 \\
2012 & 4.813 .308 & 873.882 & 408.370 & $\mathbf{3 5 . 6 3 9}$ & 0,74 & 4,08 & 8,7 \\
2013 & 4.992 .192 & 914.781 & 420.359 & $\mathbf{3 9 . 4 3 7}$ & 0,79 & 4,31 & 9,4 \\
\hline
\end{tabular}

Fonte: Adaptado a partir de SGUISSARD (2018). Elaboração dos autores.

No que se refere às políticas educacionais da educação superior, subscrevem-se os documentos:

A. Plano de Desenvolvimento da Educação (PDE) de abril 2007;

B. O Programa de Apoio a Planos de Reestruturação e Expansão das Universidades Federais (REUNI), criado pelo Decreto $\mathrm{n}^{\circ}$ 6.096, de 24 de abril de 2007;

C. O Programa Nacional de Assistência Estudantil (PNAES), que veio a ser instituído pela Portaria Normativa $\mathrm{n}^{\circ} 39$ de 12 de dezembro de 2007 e, posteriormente, no Decreto Lei $\mathrm{n}^{\circ} 7.234$ de 19 julho de 2010;

D. O Exame Nacional do Ensino Médio (ENEM), instituído pela Portaria no 807 , de 18 de junho de 2010;

E. O Sistema de Seleção Unificada (SISU), estabelecido pela Portaria Normativa $n^{\circ}$ 21, de 5 de novembro de 2012;

F. A nomeada Lei de cotas, instaurada pela Lei n 12.711, de 29 de agosto de 2012.

Por ser tratar de um conjunto de documentos que reconfiguraram a política de educação superior no Brasil vale reiterar as complexidades de suas constituições e materializações na educação superior pública, sobretudo, no caso da UFAC, única universidade pública existente no Estado do Acre e que depende quase que exclusivamente de recursos públicos da União para prover o conjunto de suas iniciativas no campo do ensino, da pesquisa e da extensão. Certamente, uma análise mais completa demandaria maior fôlego. Logo, intenciona-se, aqui, vinculá-la à reconfiguração da PAE na UFAC, tendo como marco a criação da PROAES. Nesse sentido,

\footnotetext{
${ }^{4}$ Para informações mais detalhadas sobre esse assunto, ver Sguissard (2018, p. 66).
} 
abordou-se cada documento de modo sintético, explorando apenas os elementos que consideramos indispensáveis para esta compreensão.

No que se refere ao PDE 2007, primeiro elemento nesta concepção, verifica-se que este propõe uma reconfiguração na educação nacional em todas as suas etapas. Dentre as principais constatações e intencionalidades voltadas à educação superior, por exemplo, encontram-se: a indicação das reduções do financiamento da educação superior em $50 \%$ nos períodos anteriores; a indicação de tentar resgatar em patamar mínimo os recursos de financiamento; proposição de ampliar as vagas nas IFES; ampliar e abrir cursos de graduação e licenciatura no turno noturno; inclinação de inclusão de estudantes com baixo perfil socioeconômico; e a intencionalidade de combater a evasão. Como propostas alternativas a esse enfrentamento se apresenta o REUNI e o PNAES.

Relativamente ao segundo elemento, tem-se a política ensejada pelo REUNI. No caso em análise, a proposta do REUNI UFAC 2008-2012 foi apresentada no dia 29 de outubro de 2007 ao Conselho Universitário ${ }^{5}$, e aprovada na mesma data, por 37 (trinta e sete) votos a favor, 19 (dezenove) votos contra e 06 (seis) abstenções. Após a proposta ser encaminhada à análise do Ministério da Educação (MEC), obteve, por meio do parecer dos consultores ad hoc e da Secretaria de Educação Superior (SESU), a qualificação de status: "Atente”, em 23 de novembro de 2007, e o manifesto a FAVOR da aprovação da proposta, pelo Parecer de Homologação 11, em 27 de novembro de 2007, pela Comissão de Homologações do MEC.

Assim, as condições criadas pelo Programa REUNI contribuíram para ampliar as despesas orçamentárias, correntes e de capital da UFAC. Conforme anunciamos anteriormente, tratou-se tão somente de apresentarmos, de modo sintético, alguns fragmentos das transformações ocasionadas pelo REUNI na UFAC, conforme consta no Relatório da Gestão exercício 2009 em relação às condições de infraestrutura, a saber:

Os recursos alocados para obras e projetos foram utilizados para: a) Construção de Bloco de Salas de aula com 10 salas, sendo 6 salas com capacidade para 80 alunos, medindo 93,4 $\mathrm{m} 2$ e 4 salas com capacidade para 50 alunos medindo $61,86 \mathrm{~m} 2 ; \mathrm{b}$ ) Construção do Centro de Ensino e Informação (NTI/EAD/LABORATÓRIO DE ENSINO); c) Aditivos do Restaurante Universitário e Bloco de Artes e Música;

Os recursos alocados para equipamentos e mobiliários foram utilizados para a aquisição de: a) 2 ônibus urbanos com motor de $215 \mathrm{cv}$; b) 1 ônibus rodoviário com capacidade para 44 passageiros; c) 2 veículos de passeios; d) Projetor de multimídia (para as unidades acadêmicas e administrativas); e) Equipamentos para o NTI - racks para o servidor de rede; f) 1 Servidor de rede para o NTI; g) 32 notebooks para unidades acadêmicas e administrativas; h) 4 filmadoras portáteis (curso de jornalismo); i) Equipamentos diversos para unidades acadêmicas e administrativas (UFAC/RELATÓRIO DA GESTÃO, 2009, p. 13, grifo do autores).

De outra feita, é notório reconhecer também que o REUNI contribuiu para a ampliação efetiva do corpo docente e técnico-administrativo ${ }^{6}$, bem como a ampliação da oferta do número

\footnotetext{
${ }^{5}$ Conforme Ata da $3^{a}$ reunião extraordinária do Conselho Universitário Mantado 2006. O REUNI foi aderido pela UFAC conforme consta na Resolução no 13 do CONSU, de 29 de outubro de 2009.

6 “Ampliação do quadro de pessoal, sendo 42 docentes e 46 técnicos administrativos" (UFAC/RELATÓRIO DA GESTÃO, 2010 p. 14).
} 
de vagas nos cursos de graduação na IES, seja pela ampliação do número de vagas nos cursos já existentes $^{7}$, seja pela criação de novos cursos com a indução para abertura de cursos no período noturno. Nesse sentido, as receitas financeiras, a partir do REUNI, possibilitaram redesenhar os espaços de infraestrutura física, equipamentos e suporte acadêmico e pedagógico para assegurar a efetivação do aumento de vagas de ingresso, ocupação de vagas ociosas (em especial, noturna), mobilidade acadêmica intra e interinstitucional, inclusão, assistência estudantil, expansão da pósgraduação stricto sensu, contratação de pessoal docente e técnico-administrativo, dentre outros ${ }^{8}$.

Nessa linha de argumentação se apresenta então o terceiro elemento, que corresponde ao cenário de escala crescente dos repasses financeiros realizados pelo Ministério da Educação (MEC) para efetivação das ações do PNAES. O Gráfico 1, possibilita observar uma dimensão mais precisa desta escala crescente, elaborado a partir dos dados disponíveis no portal do Sistema Integrado de Planejamento e Orçamento (SIOP), especificamente na plataforma do Painel do Orçamento Federal, considerando a série Dotação Atual $^{9}$ e os filtros, Ano: 2008 a 2019; Ação ${ }^{10}: 4002$ Assistência ao Estudante do Ensino de Graduação $^{11}$ e 4002 - Assistência ao Estudante de Ensino Superior ${ }^{12}$; e Unidade Orçamentária: 26275 - Fundação Universidade Federal do Acre.

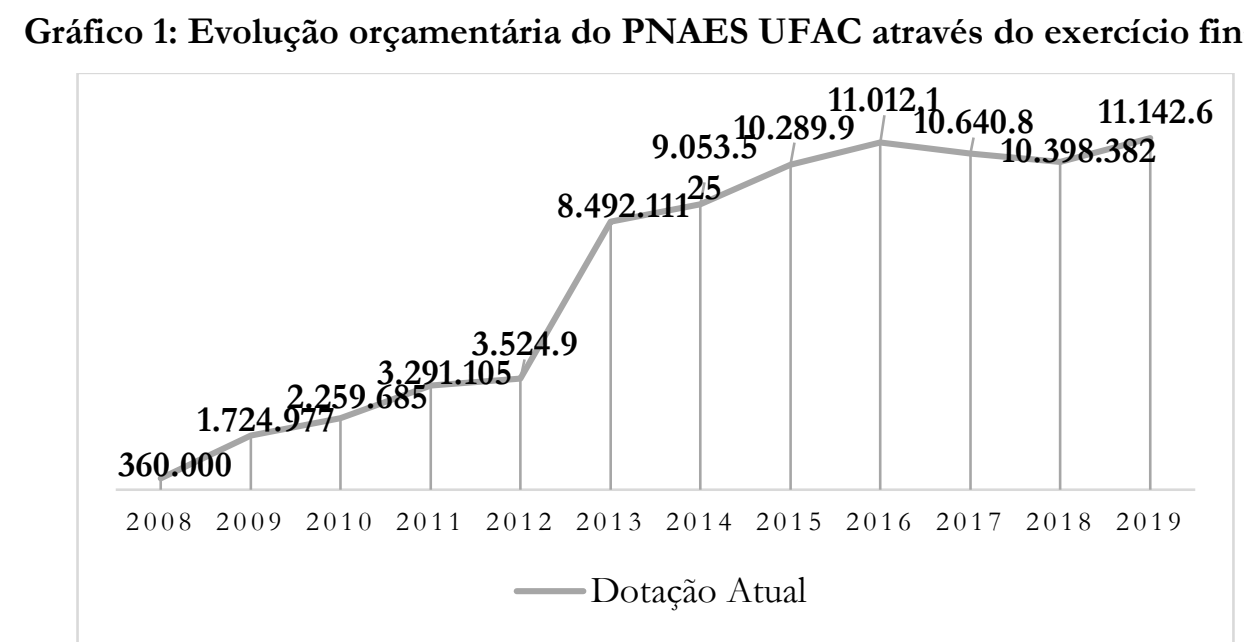

Fonte: SIOP - Painel do Orçamento Federal. Gráfico elaborado pelos autores.

\footnotetext{
7 “Curso de Engenharia Elétrica ofertando 50 vagas em período integral” (UFAC/RELATÓRIO DA GESTÃO, 2010 p. 14).

${ }^{8}$ Vale lembrar que todo esse processo amplo e complexo do REUNI na UFAC não se deu em total tom de consenso e convergências, entretanto, por fidelidade ao objeto deste estudo, teve-se condições efetivas de tecer uma análise mais profunda.

${ }^{9}$ Valor inicial acrescido e/ou reduzido pelos créditos e/ou alterações aprovados na Lei Orçamentária Anual.

10 Ação corresponde a: “Operação da qual resultam produtos (bens ou serviços) que contribuem para atender ao objetivo de um programa. Incluem-se também no conceito de ação as transferências obrigatórias ou voluntárias a outros entes da Federação e a pessoas físicas e jurídicas, na forma de subsídios, subvenções, auxílios, contribuições, entre outros, e os financiamentos". Disponível em: https://www.tesourotransparente.gov.br/sobre/glossario-dotesouro-nacional. O número 4002 confere a identificação da Ação do PNAES no Orçamento Federal.

${ }^{11}$ Identificação referente aos períodos de 2008 a 2011.

12 Identificação referente aos períodos de 2012 a 2019.
} 
A partir dos dados constantes no Gráfico 1, nota-se uma significativa diferença no orçamento assegurado entre os exercícios dos anos de 2012 e 2013. O acréscimo soma mais que o dobro da receita, o que corresponde, especificamente, a um montante de $\mathrm{R} \$ 4.967 .195,00$ (quatro milhões, novecentos e sessenta e sete mil, cento e noventa e cinco reais) a mais garantidos no orçamento, com a finalidade de ampliar as condições de permanência dos estudantes matriculados na educação superior pública federal.

Indubitavelmente, tais influências externas incidiram no contexto prático da materialização da PAE na UFAC, se considerarmos, principalmente, que anteriormente a tais fatos, as ações de gerenciamento e execução vinculadas à PAE e, por consequência, ao PNAES, face às diretrizes nacionais, perpassaram por diferentes setores administrativos da instituição, conforme pode ser extraído das informações constantes na síntese exposta no Quadro 1.

Quadro 1: Evolução orçamentária do PNAES UFAC através do exercício financeiro anual

\begin{tabular}{|c|l|}
\hline Ano & \multicolumn{1}{|c|}{ Setor responsável pelo gerenciamento ou execução da ação } \\
\hline 2008 & $\begin{array}{l}\text { Pró-Reitoria de Graduação (PROGRAD) } \\
\text { Pró-Reitoria de Extensão e Cultura (PROEX) e unidades de apoio: } \\
\text { Diretoria de Ação Comunitário (DAC) }\end{array}$ \\
\hline 2009 & $\begin{array}{l}\text { Pró-Reitoria de Graduação (PROGRAD) } \\
\text { Pró-Reitoria de Extensão e Cultura (PROEX) e unidades de apoio: } \\
\text { Diretoria de Ação Comunitário (DAC) e a Diretoria de Arte, Cultura e Assuntos Estudantis } \\
\text { (DACAE) }\end{array}$ \\
\hline 2010 & $\begin{array}{l}\text { Pró-Reitoria de Extensão e Cultura (PROEX) e unidades de apoio: } \\
\text { Diretoria de Assuntos Comunitário (DAC) }\end{array}$ \\
\hline 2011 & \begin{tabular}{l} 
Diretoria de Arte, Cultura e Assuntos Estudantis (DACAE) \\
\hline 2012
\end{tabular} \\
\hline
\end{tabular}

Fonte: Relatório de Gestão da UFAC, período de 2008 a 2012. Quadro elaborado pelos autores.

Conforme identificado nos Relatórios de Gestão dos anos 2008 a 2012, os órgãos de gerenciamento ou execução do PNAES passaram por duas Pró-Reitorias Acadêmicas, a PROGRAD e a PROEX, e também pela Diretoria de Ação Comunitário (DAC) e Diretoria de Arte, Cultura e Assuntos Estudantis (DACAE), unidades de apoio vinculadas à PROEX. Ainda que a PROGRAD e a PROEX constem como gerenciadoras e executoras das ações do PNAES, acredita-se que durante esse período a DAC e a DACAE tenham atuado como unidades a frente das ações de PAE.

Desse modo, buscou-se conhecer melhor a DAC e da DACAE. Em consulta às Resoluções, Atas Aprovadas Ad Referendum dos períodos de 1997 a 2019 do Conselho Universitário (CONSU), órgão máximo normativo e deliberativo da política universitária e a última instância recursal, não se encontrou nenhuma menção que vinculasse a DAC à estrutura administrativa das Pró-Reitorias Administrativas ou Acadêmicas da UFAC, pese o fato de a mesma constar referenciada nos Relatórios de Gestão de 2008 a 2010:

Diretoria de Ação Comunitária

Atividade: Programa Institucional de Assistência Estudantil - PIAE

Objetivo: Dar suporte aos acadêmicos com auxílio transporte e alimentação

Público-alvo: Alunos da instituição com dificuldades financeiras

Promoção: Diretoria de Ação Comunitária

Realização: Diretoria de Ação Comunitária 
Apoio Cultural: Coordenadoria de Cultura e Assuntos Estudantis - PROEXC (UFAC/RELATÓRIO DA GESTÃO, 2008, p. 45).

Uma das ações que compõem a assistência ao educando do ensino de graduação prestada através da Diretoria de Ação Comunitária é o fornecimento de refeições no Restaurante Universitário. Em 2009 o RU da UFAC ofereceu 116.464 refeições (almoço e jantar). Atualmente o RU fornece em média 320 refeições /dia [...] (UFAC/RELATÓRIO DA GESTÃO, 2009, p. 19).

Uma das ações que compõem a assistência ao estudante do ensino de graduação prestada através da Diretoria de Ação Comunitária - DAC é o fornecimento de refeições no Restaurante Universitário, que serve refeições de almoço e jantar à toda comunidade (UFAC/RELATÓRIO DA GESTÃO, 2010, p. 125).

Ainda que tenhamos identificado a gestão e a execução dos recursos do PNAES efetivadas pela DAC durante esse período, não foram encontrados, nos documentos (Relatório de Gestão e documentos do CONSU), um delineamento detalhado sobre a estrutura administrativa responsável. O que mais se aproxima a essa questão são os termos da Resolução no ${ }^{\circ}$ 62, de 14 de setembro de 2009 do CONSU, que aprovou a Estrutura Administrativa das Pró-Reitorias Administrativas e Pró-Reitorias Acadêmicas da Universidade Federal do Acre, cuja referência mais explícita consta no organograma da Pró-Reitoria de Extensão e Cultura:

\section{Pró-Reitoria de Extensão e Cultura}

1.1. Secretaria Executiva

1.2. Diretoria de Programas do Projeto de Extensão

1.2.1. Secretaria

1.2.2. Coordenadoria de Formação Continuada

1.2.3. Coordenadoria de Programas e Projetos de Extensão

1.2.4. Coordenadoria de Estágio

\subsection{Diretoria de Assuntos Comunitários}

2.3.1 Secretaria

2.3.2 Coordenadoria do Restaurante Universitário

2.3.3 Coordenadoria do Anfiteatro

2.3.4 Coordenadoria do Serviço de Saúde Estudantil

1.4. Diretoria de Arte, Cultura e Assuntos Estudantis

1.4.1. Secretaria

1.4.2. Coordenadoria de Arte e Cultura

1.4.3. Coordenadoria de Assuntos Estudantis

1.4.4. Coordenadoria de Assistência Social

(UFAC/Resolução no 62 do CONSU, 2009).

Todavia, na análise do organograma verificamos que não trata do detalhamento das finalidades, responsabilidades e atribuições de cada uma das unidades administrativas que compõem a PROEX, tampouco faz constar representada a Diretoria de Ação Comunitária. Porém, sobre a Diretoria de Assuntos Comunitário, a par dessa indefinição, presume-se um eventual ruído de comunicação no que se refere aos dados apresentados à Pró-Reitoria de Planejamento (PROPLAN), unidade responsável pela elaboração do Relatório de Gestão. 
$\mathrm{Na}$ continuidade do estudo tem-se o quarto elemento, qual seja, a adesão ao Exame Nacional do Ensino Médio (ENEM) pela UFAC, como processo de seleção para ingresso nos cursos de graduação. Essa ação ocorreu, em um primeiro momento, no ano de 2009, como uma opção somente para o preenchimento das vagas remanescentes, isto é, aquelas que não foram preenchidas no Concurso Vestibular ${ }^{13}$. No ano de 2010 , fora acrescida a adesão para as vagas totais para o ano letivo de 2011 do curso de licenciatura em Filosofia e de 50\% das vagas do curso de Licenciatura em Música ${ }^{14}$. Nesse trilhar, ocorreu que, no ano de 2011, a adesão foi integral, ficando estabelecido que, para o ano letivo de 2012, a forma de ingresso nos cursos de graduação da UFAC seria efetivada integralmente pela seleção via $\mathrm{ENEM}^{15}$.

O Relatório de Gestão do exercício de 2011 destaca que essa opção "veio a ampliar a oportunidade para os jovens do interior do estado, assim como para os jovens dos demais estados brasileiros" (UFAC/RELATÓRIO DA GESTÃO, 2011, p. 12), perspectiva esta que se aproxima ao pensamento de Andriola (2011) que vê o ENEM como instrumento que possibilitou maiores chances para o acesso à educação superior, em especial, dos estudantes menos favorecidas economicamente, considerando as suas impossibilidades de custear o deslocamento para a realização da prova vestibular fora da sua cidade. Em consideração a esse aspecto, são significavas as possibilidades que o ENEM trouxe como alternativa de ingresso à educação superior pública.

Por conseguinte, tem-se o quinto elemento, a adesão ao Sistema de Seleção Unificada (SISU), que ocorreu no dia 18 de abril de 2011, através da Resolução no 13 do CONSU. Nessa Resolução consta a decisão favorável à adesão ao ENEM/SISU sem, no entanto, fazer constar a definição prévia do percentual desta adesão, ou seja, sem a indicação total ou parcial da composição dos cursos de graduação que passariam a ter a nota do ENEM processada pelo SISU como elemento de seleção para o ingresso. $\mathrm{Na}$ análise que pudemos manusear verificamos que essa informação foi disponibilizada no final do exercício da gestão em 2011: "tivemos dois cursos que ofertaram vagas pelo SISU (Sistema de Seleção Unificada), são eles: música (20 vagas ofertadas pelo SISU) e filosofia (50 vagas ofertadas pelo SISU)" (UFAC/RELATÓRIO DA GESTÃO, 2011, p. 109).

Assim sendo, verificamos então que a adesão de forma mais ampla da UFAC ao SISU ocorreu somente no ano de $2012^{16}$. Nesse cenário, a IES optou por aderir totalmente ao SISU para proceder a seleção com base na nota obtida no ENEM, com ressalvas quanto a aplicação deste procedimento para os casos dos cursos de graduação em Música, dadas às especificidades estabelecidas no seu Projeto Pedagógico Curricular. Nesse movimento, a UFAC tratou de publicar o Edital no 01/2012 - PROGRAD, que regulamentava o processo Seletivo para o ingresso nos cursos de graduação nos $1^{\circ}$ e $2^{\circ}$ semestres de 2013, por meio do SISU, edição no $01 / 2013^{17}$.

O sexto elemento diz respeito à promulgação da Lei no 12.711 , de 29 de agosto de 2012, regulamentada através do Decreto $n^{\circ} 7.824$, de 11 de outubro de 2012, popularmente conhecida como "Lei de Cotas", que dispõe sobre o ingresso nas universidades federais e nas instituições federais de ensino técnico de nível médio, proferindo que

Art. 1o As instituições federais de educação superior vinculadas ao Ministério da Educação reservarão, em cada concurso seletivo para ingresso nos cursos de

\footnotetext{
${ }^{13}$ Conforme Resolução no 25 do CONSU de 12 de maio de 2009.

${ }^{14}$ Conforme Resolução no 36 do CONSU de 05 de julho de 2010.

${ }^{15}$ Conforme Resolução no 16 do CONSU de 26 de maio de 2011.

${ }^{16}$ Conforme Resolução no 19 do CONSU de 27 de junho de 2012.

${ }^{17}$ Conforme Resolução n ${ }^{\circ} 98$ do CONSU de 29 de novembro de 2012.
} 
graduação, por curso e turno, no mínimo 50\% (cinquenta por cento) de suas vagas para estudantes que tenham cursado integralmente o ensino médio em escolas públicas.

Parágrafo único. No preenchimento das vagas de que trata o caput deste artigo, $50 \%$ (cinquenta por cento) deverão ser reservados aos estudantes oriundos de famílias com renda igual ou inferior a 1,5 salário-mínimo (um salário-mínimo e meio) per capita (BRASIL, 2012).

Art. $8^{\circ}$ As instituições (...) implementarão, no mínimo, vinte e cinco por cento da reserva de vagas a cada ano, e terão até 30 de agosto de 2016 para o cumprimento integral do disposto neste Decreto (BRASIL, 2012a).

Desse modo, considerando um novo cenário que se apresentava na UFAC advindo pelas transformações que decorreram da materialização da Lei de Cotas e do Decreto da sua regulamentação. Seguramente, uma parcela dos perfis socioeconômicos e culturais dos estudantes que pleiteariam ingressar no ano de 2013 também se transformaria por conta da atenção às reservas de vagas destinadas a um público especifico - estudantes que cursaram integralmente o ensino médio em escola pública e estudantes oriundos de famílias com renda igual ou inferior a 1,5 salário mínimo. Nesse sentido, é concebível que tal fato exigisse também transformações na estrutura administrativa da UFAC a fim de melhor receber os estudantes absorvidos por esses "novos" perfis.

Dentro desta nova ambiência institucional presume-se, por seu turno, que os eventos principais que levaram a uma reorganização administrava, acadêmica e pedagógica da UFAC relativamente à gestão e execução da PAE, ocorreram, sobretudo, em decorrência dos elementos aqui explicitados - financiamento das Instituições Federais de Ensino Superior (IFES) e das políticas educacionais do ensino superior nacional - ou seja, elementos externos à gestão da UFAC.

Contudo, não se pode desconsiderar que as transformações da gestão e execução da PAE ocorridas na UFAC estejam circunscritas somente a elementos externos, pois, se assim fosse, as arenas internas da UFAC, inclusive as disputas eletivas e as ações práticas isto é, o ambiente onde os profissionais atuam no contexto da prática, seria totalmente desconsideradas ou secundarizadas como elemento que também condiciona e pauta o curso das transformações.

Assim, vale aqui reiterar o que Mainardes (2006) assinala ao apresentar o referencial teóricometodológico da Abordagem do Ciclo de Política, em especial o contexto da prática. O autor destaca que, além da formação dos discursos que constituem os textos políticos - e, por consequência, os cenários políticos - tem-se que considerar "a interpretação ativa que os profissionais que atuam no contexto da prática fazem para relacionar os textos da política à prática" (MAINARDES, 2006, p. 50).

Ainda que se leia que na ambiência interna da UFAC a criação da PROAES foi o primeiro elemento prático da ação dos atores sociais e institucionais, reconhece-se que necessário se faz discutir em um mergulho atento e mais profundo nesse contexto da prática, campo onde atuam os profissionais numa relação em que estão imbricados aos contextos e textos políticos externos. Contudo, dado os limites desse artigo, tal questão ficará para uma outra conversa.

\section{CONSIDERAÇÕES FINAIS}

Verificou-se, na análise documental, que no penúltimo mês do exercício de 2012, ocorreu uma reestruturação relativa a execução, coordenação e materialização das Políticas de Assistência 
Estudantil no âmbito da UFAC. Com base na análise realizada, conclui-se que o convite de natureza impositiva, movido pelas mudanças de perspectivas acerca das sistemáticas transferências de recursos e das reconfigurações das políticas públicas educacionais para o ensino superior, intimou a UFAC, a exemplo das demais IFES, a seguir um ritmo distinto frente às opções ensejadas pelo Ministério da Educação (MEC), as quais, metaforicamente definem-se, aqui, como: aceite e acerte os passos ao ritmo da dança ou decline do convite e não compareça ao baile.

Nesse sentido, a UFAC, no afã de aceitar e acertar os passos ao ritmo da dança, impunhase a necessidade de reordenar sua gestão às regras vigentes para participar do baile, de modo a ter acesso à festa e ao bolo da festa ${ }^{18}$, posto que isso viria a possibilitar uma expansão de suas ações acadêmicas. O oposto disso era ter que responder, cedo ou tarde, ao MEC, acerca do não cumprimento das normas vigentes e infrações como, por exemplo, a não efetivação da Lei de Cotas, $n^{\circ} 12.711$, além das restrições para poder acessar recursos extra ao orçamento.

De certo, o principal reordenamento da UFAC, no campo da gestão e execução das políticas de assistência estudantil, foi a constituição de um órgão executivo específico para cumprir esta finalidade, desencarregando, especialmente, a Pró-Reitoria de Extensão e Cultura (PROEX) dessa função. Dada a requisição - quase que impositiva - do contexto externo e coadjuvada, também, pela leitura dos cenários realizada pelos atores ${ }^{19}$ da gestão da UFAC, ter uma estrutura específica e exclusiva para acertar os passos ao ritmo da dança se apresentou como a alternativa mais acertada constituindo-se nesse cenário como primeira ação do contexto prático do PNAES na UFAC no período dos anos de 2013.

Assim, a partir daquela conjuntura até os dias atuais, a PAE efetivada na UFAC encontrase sobe a incumbência institucional da PROAES, cuja responsabilidade constitui-se núcleo central e pilar constitutivo desde a sua criação, visto que conforme consta no Regimento Geral da Universidade Federal do Acre (2013), sua finalidade ancora-se em ser: "Art. 157. [...] o órgão responsável pelo planejamento e execução da política de assistência estudantil da Universidade Federal do Acre. Tem como finalidade promover ações afirmativas de acesso e inclusão social que buscam garantir a igualdade de oportunidades aos estudantes" (UFAC/REGIMENTO INTERNO, p. 56, 2013).

\section{REFERÊNCIAS}

BRASIL. Decreto n 6.096, de 24 de abr. de 2007. Institui o Programa de Apoio a Planos de Reestruturação e Expansão das Universidades Federais - REUNI. Disponível em: http://www.planalto.gov.br/ccivil_03/_Ato2007-2010/2007/Decreto/D6096.htm. Acesso em 08 de mar. de 2020.

BRASIL. Decreto $n^{\circ} 7.234$, de 19 de jul. de 2010. Dispõe sobre o Programa Nacional de Assistência Estudantil - PNAES. Disponível em: http://www.planalto.gov.br/ccivil_03/_Ato20072010/2010/Decreto/D7234.htm. Acesso em 08 de mar. 2020.

BRASIL. Decreto n ${ }^{\circ} 7.824$, de 11 de out. de 2012. Regulamenta a Lei no 12.711 , de 29 de agosto de 2012, que dispõe sobre o ingresso nas universidades federais e nas instituições federais de ensino

\footnotetext{
${ }^{18}$ Festa: aval de não sofrer sanções administrativas; bolo da festa, acessar os repasses financeiros extra orçamento, como é o caso do REUNI e o PNAES.

19 Aqui, percebe-se nitidamente a atuação dos atores locais na prática da política do PNAES, ainda que de forma indireta, pois não houve uma ação executiva desta, mas uma ação que preparava o cenário para a sua atuação executiva.
} 
técnico de nível médio. Disponível em: http://www.planalto.gov.br/ccivil_03/_ato20112014/2012/decreto/d7824.htm. Acesso em 08 de mar. 2020.

BRASIL. Lei $n^{\circ} 12.711$, de 29 de ago. de 2012. Dispõe sobre o ingresso nas universidades federais e nas instituições federais de ensino técnico de nível médio e dá outras providências. Disponível em: http://www.planalto.gov.br/ccivil_03/_ato2011-2014/2012/lei/112711.htm. Acesso em 08 de mar. 2020.

BRASIL. O plano de desenvolvimento da educaşão razões, princípios e programas. Disponível em: http://portal.mec.gov.br/arquivos/livro/livro.pdf. Acesso em 08 de mar. 2020.

BRASIL. Portaria MEC n 807, de 18 de jun. de 2010. Disponível em:

https://abmes.org.br/legislacoes/detalhe/1792/portaria-mec-n-807. Acesso em 08 de mar. 2020.

BRASIL. Portaria Normativa No 21, de 21 de dez: de 2012. Disponível em:

https://abmes.org.br/legislacoes/detalhe/2D297/portaria-normativa-n-21. Acesso em 08 de mar. 2020.

BRASIL. Portaria Normativa nº 39, de 12 der: 2007. Institui o Programa Nacional de Assistência Estudantil - PNAES. Disponível em:

http://portal.mec.gov.br/arquivos/pdf/portaria_pnaes.pdf. Acesso em 08 de mar. 2020.

FONAPRACE, Fórum Nacional de Pró-reitores de Assuntos Comunitários e Estudantis. Revista FONAPRACE: 20 Anos 1987-2007. Brasília, 2008.

GONÇALVES, R. M. Bricolagens praticadas e politicaspráticas de curriculos nos cotidianos escolares / Rafael Marques Gonçalves. Rio de Janeiro/ UERJ, 2018.

GONÇALVES, R. M. Autonomia e Políticaspráticas de Currículos: uma equação entre raízes e opções. Educ. Real., Porto Alegre , v. 44, n. 3, e84870, 2019 . Available from $<$ http:/ / www.scielo.br/scielo.php?script=sci_arttext\&pid=S2175-

62362019000300401\&lng $=$ en\&nrm $=$ iso $>$. access on 26 May 2020. Epub Sep 12, 2019. https://doi.org/10.1590/2175-623684870.

GONÇALVES, R. M;et at all. A BNCC NA CONTRAMÃO DAS DEMANDAS SOCIAIS: PLANEJAMENTO COM E PLANEJAMENTO PARA. Práxis Educacional, [S.l.], v. 16, n. 38, p. 338-351, jan. 2020. ISSN 2178-2679. Disponível em: $<$ http://periodicos2.uesb.br/index.php/praxis/article/view/6012>. Acesso em: 26 maio 2020. doi: https://doi.org/10.22481/praxisedu.v16i38.6012.

GONÇALVES, R. M. CONVERSAS SOBRE PRÁTICAS E CURRÍCULOS ENTRE PROFESSORAS: ARTESANIA E MANEIRAS DE FAZER O COTIDIANO ESCOLAR. Linguagens, Educação e Sociedade, Teresina, Ano 23, Edição Especial, dez. 2018. Disponível em: https://revistas.ufpi.br/index.php/lingedusoc/article/view/7876. Acesso em 26 de maio de 2020. Doi: https://doi.org/10.26694/les.v1i1.7876

KOWALSKI, Aline Viero. Os (des) caminhos da política de assistência estudantil e o desafio na garantia de direitos. 179 f. Tese (Doutorado em Serviço Social). Pontifícia Universidade Católica do Rio Grande do Sul - PUCRS, 2012.

MAINARDES, Jefferson. Abordagem do ciclo de políticas: uma contribuição para a análise de políticas educacionais. Educação e Sociedade, Campinas, v. 27, n.94, p. 47-69, 2006.

SGUISSARDI, Valdemar. Estudo Diagnóstico da Politica de Expansão da (e Acesso à) Educação Superior no Brasil - 2002-2012. Brasília: Edital N. 051/2014 SESU; Projeto de Organismo Internacional OEI; Projeto OEI/BRA/10/002, Versão revisada e corrigida em jun/2018, 2014. 
UNIVERSIDADE FEDERAL DO ACRE. Regimento geral da Universidade Federal do Acre. Rio Branco, Acre, 2013. Disponível em: http://www2.ufac.br/site/reitoria/competencias. Acesso em 08 de mar. 2020.

UNIVERSIDADE FEDERAL DO ACRE. Relatórios da Gestão exercícios. Edições de 2008 a 2017. Disponíveis em: http://www.ufac.br/site/ufac/proplan/relatorios-de-gestao. Acesso em 08 de mar. 2020

UNIVERSIDADE FEDERAL DO ACRE. Resolução No 13; 16/2011, Conselho Universitário (CONSU).

UNIVERSIDADE FEDERAL DO ACRE. Resolução Nº 19; 98; 99/2012, Conselho Universitário (CONSU).

UNIVERSIDADE FEDERAL DO ACRE. Resolução No 25; 62/2009, Conselho Universitário (CONSU).

UNIVERSIDADE FEDERAL DO ACRE. Resolução Nº 36/2010, Conselho Universitário (CONSU).

XAVIER SILVA, Adão Rogério. A materialização do Programa Nacional de Assistência Estudantil na Universidade Federal do Acre: texto, contexto, processos e práticas. Dissertação (Mestrado em Educação). Universidade Federal de Acre - UFAC, 2019.

Submetido em março de 2020. Aprovado em abril de 2020.

\section{Informações do (a)(s) autor(a)(es)}

Adão Rogério Xavier Silva

Mestre em Educação (UFAC). Membro do Núcleo de Estudos e Pesquisas em Política Educacional, Gestão e Financiamento da Educação da Universidade Federal do Acre/UFAC.

E-mail: adaorxs@gmail.com

ORCID: https:// orcid.org/0000-0003-0277-3392

Link Lattes: http://lattes.cnpq.br/0972894075035313

Mark Clark Assen de Carvalho

Doutor em Educação (PUC-SP). Professor Titular do Centro de Educação, Letras e Artes da Universidade Federal do Acre/UFAC e Professor Permanente do Programa de Pós-Graduação em Educação da UFAC e do Doutorado em Rede/EDUCANORTE. Bolsista de Pós-doutorado CAPES/PROCAD.

E-mail:markassen@yahoo.com.br

ORCID: https://orcid.org/0000-0003-3638-9719

Link Lattes: http://lattes.cnpq.br/0736995836464424

Rafael Marques Gonçalves

Doutor em Educação (UERJ/PROPED). Professor da Universidade Federal do Acre vinculado ao quadro permanente de docentes no Programa de Pós-Graduação em Educação PPGE/UFAC.

E-mail: rafamg02@gmail.com

ORCID: https://orcid.org/0000-0002-9038-1542

Link Lattes: http://lattes.cnpq.br/0460662499829326 